\title{
ANALISIS KEBUTUHAN UDARA UNTUK MERANCANG SISTEM VENTILASI AMAN
}

\section{ANALYSIS OF AIR REQUIREMENT TO DESIGN A SAFE VENTILATION SYSTEM}

\author{
Riyamizard Z1 ${ }^{1}$ M. Taufik Toha ${ }^{2}$, Syamsul Komar ${ }^{3}$ \\ ${ }^{1-3}$ Magister Teknik Pertambangan, Fakultas Teknik, Universitas Sriwijaya \\ Jalan Raya Palembang-Prabumulih, KM 32 Inderalaya Kabupaten Ogan Ilir 30662 \\ e-mail: ${ }^{1}$ riyamizardzazili@gmail.com ${ }^{2}$ taufiktoha@yahoo.com
}

\begin{abstract}
ABSTRAK
Tambang bawah tanah (Underground Mining) adalah suatu sistem penambangan yang kegiatannya dilakukan di bawah permukaan bumi. Sistem ventilasi yang digunakan CV. Bara Mitra Kencana adalah ventilasi hembus, bertujuan untuk menyediakan dan mengalirkan udara segar ke dalam tambang bagi pernafasan pekerja dan proses lain yang memerlukan udara. Pada lokasi lubang tambang BMK 35 lori 4 pernah terjadi kecelakaan kerja akibat kurangnya suplai oksigen menyebabkan kematian dua orang pekerja. Dari hasil pengukuran gas menggunakan alat multigas detector didapatkann kandungan gas methan $\mathrm{CH}_{4}$ sebesar $7 \mathrm{LEL}$ dan gas CO 36 PPM. Sistem forcing (hembus) menggunakan blower 14 Inch dan 12 Inch, debit udara yang dihasilkan sudah melebihi standar $\left(2 \mathrm{~m}^{2} / \mathrm{menit}\right)$ akan tetapi gas-gas berbahaya belum dapat terurai dengan baik. Oleh karena itu, re-design ventilasi diperlukan dengan menerapkan sistem ventilasi forcing overlap, yaitu perpaduan sistem hembus dengan hisap dengan menempatkan blower pada lokasi 8 meter sebelum cabang C6 pada saluran udara masuk. Selanjutnya pada dekat lokasi kerja dipasang exhaust untuk menarik udara segar yang tersirkulasi ke lokasi Front kerja (FK). Pada lokasi front kerja ditambahkan satu (1) exhaust agar membantu menarik udara keluar menuju pintu masuk.
\end{abstract}

Kata kunci: ventilasi, udara, rancangan

\section{ABSTRACT}

Underground mining is a mining system whose activities are carried out below the earth's surface. The ventilation system used by CV. Bara Mitra Kencana is an exhaled vent, which aims to provide and circulate fresh air into the mine for the breathing of workers and other processes that require air. At the BMK 35 lorry 4 mining pit location, a work accident occurred due to lack of oxygen supply causing the death of 2 workers. From the results of gas measurements using a multigas detector, the content of methane $\mathrm{CH} 4$ gas is $7 \mathrm{LEL}$ and $\mathrm{CO}$ gas 36 PPM. The forcing system (blowing) uses a 14 Inch and 12 Inch blower, the resulting air flow exceeds the standard $(2 \mathrm{~m} 2 / \mathrm{min})$, but the harmful gases cannot be decomposed properly. Therefore, a re-design of ventilation is needed by applying a forcing overlap ventilation system, which is a combination of a blowing and suction system by placing the blower at a location 8 meters before the C6 branch on the intake air duct. Then near the work site an exhaust is installed to draw fresh air that is circulated to the work front location (FK). At the work front location added 1 exhaust to help draw air out towards the entrance.

Keyword: ventilation, air, design 


\section{Jurnal Pertambangan}

\section{PENDAHULUAN}

Tambang bawah tanah (Underground Mining) merupakan sistem penambangan yang kegiatan dan aktivitas dilakukan di bawah permukaan bumi [1]. CV. Bara Mitra Kencana merupakan perusahaan penambangan batubara yang melakukan kegiatannya dengan menggunakan sistem tambang bawah tanah. Kegiatan penambangannya dilakukan dengan menggunakan metode room and pillar [1]. Sistem ventilasi pada kegiatan tambang bawah tanah adalah hal yang sangat penting karena aliran udara terbatas dan terdapat gas-gas berbahaya yang dapat menyebabkan kecelakaan tambang seperti methan $\left(\mathrm{CH}_{4}\right)$, karbondioksida $\left(\mathrm{CO}_{2}\right)$, karbon monoksida (CO), hidrogen Sulfida $\left(\mathrm{H}_{2} \mathrm{~S}\right)$, sulfur dioksida $\left(\mathrm{SO}_{2}\right)$, nitrogen oksida $\mathrm{NO}_{\mathrm{X}}$ ), dan gas lainnya.

Ventilasi yang digunakan pada CV. Bara Mitra Kencana adalah sistem hembus yang bertujuan untuk memberikan suplai udara ke dalam lubang tambang untuk para pekerja dan mengurai konsentrasi gas-gas berbahaya. Akibat kurang optimalnya sistem ventilasi di antaranya yaitu terjadi ledakan gas metana, kekurangan oksigen sehingga menyebabkan sulitnya bernafas, dan terhirupnya gas-gas beracun bagi para pekerja, seperti yang pernah terjadi di perusahaan ini pada Januari 2020 lokasi BMK 35 Lori 4. Kecelakaan ini menyebabkan meninggalnya dua orang pekerja akibat kurangnya suplai oksigen pada lokasi kemajuan tambang. Pada lokasi yang sama pada bulan Oktober 2020 terjadi ledakan tambang akibat gas methan yang melebihi nilai ambang batas akan tetapi tidak ada pekerja yang menjadi korban dikarenakan terjadi pada hari libur. Oleh sebab itu kepala teknik tambang mengambil kebijakan untuk metutup semantara lokasi tersebut dan arah kemajuan penambangan dipindahkan ke sebelah kanan dari lokasi.

Untuk dapat memenuhi kebutuhan udara para pekerja di tambang bawah tanah perlu dilakukan pengkajian terhadap jumlah pekerja, emisi gas metana dan gas lainnya, peralatan yang beroperasi serta kondisi temperatur dan kelembaban udara. Dengan dilakukan pengkajian parameter ini dapat ditentukan temperatur efektif dan kelembaban relatif front kerja untuk memenuhi kebutuhan udara segar baik untuk pekerja. Perlu adanya perencanaan sistem ventilasi yang baik untuk memberikan suplai udara agar dapat memenuhi kebutuhan oksigen para pekerja $2 \mathrm{~m}^{3} /$ menit, serta menstabilkan temperatur $18-24^{\circ} \mathrm{C}$ dengan kelembaban relatif $85 \%$. Oleh karena itu, studi ini dibuat dengan tujuan untuk melakukan re-design sistem ventilasi yang aman di BMK 35 Lori 4.

\section{METODE PENELITIAN}

Penelitian dilakukan di BMK 35 Lori 4 CV. Bara Mitra Kencana Tanah Kuning, Desa Batu Tanjung Kecamatan Talawi, Kota Sawahlunto, Provinsi Sumatera Barat. Dalam penelitian ini akan dilakukan pengumpulan data dengan metode kuantitaif, analisis data, interpretasi data, merumuskan kesimpulan berdasarkan analisis data tersebut.

\section{Pelaksanaan Penelitian}

Tahapan pelaksanaan pada penelitian ini dimulai dari persiapan lalu penelitian lapangan. Pada tahap persiapan, dilakukan studi pustaka terlebih dahulu untuk mengumpulkan informasi awal dan literatur-literatur yang ada. Selain itu menyiapkan keperluan administrasi seperti surat-menyurat, surat izin, dan surat pengantar.

Tahapan selanjutnya yaitu penelitian lapangan ditujukan untuk melakukan berbagai pengukuran seperti pengukuran luas penampang terowongan, gas, kecepatan aliran udara, temperatur efektif dan kelembaban relatif serta pemantauan investigasi lokasi terjadinya kecelakaan.

\section{Pengolahan Data}

Data yang sudah diambil akan diolah dan dihitung sesuai dengan rumus persamaan yang telah ditetapkan.

\section{Perhitungan Luas Penampang Terowongan}

Pada perhitungan luas tambang terowongan menggunakan persamaan berikut, (Refky Adi Nata, 2019).

luas elips $=a \times b \times \pi$

luas setengah elips $=\frac{a \times b \times \pi}{2}$.....

$A=p x \lambda$

$\mathrm{A}=$ Luas penampang persegi panjang

\section{Perhitungan Kandungan Rata-Rata Gas}

Kandungan gas seperti $\mathrm{CO}, \mathrm{CO}_{2}, \mathrm{CH}_{4}, \mathrm{H}_{2} \mathrm{~S}$, dan $\mathrm{O}_{2}$ diukur setiap hari selama 2 minggu, kemudian dijumlahkan dan diakumulasikan untuk mendapatkan rata-rata dari konsentrasi gas di lokasi tersebut.

\section{Menghitung Debit Udara}

Persamaan debit udara dihitung dengan persamaan berikut, (Hartaman H.L, 2012)

$Q=v \times A$ 


\section{Jurnal Pertambangan}

Menghitung Temperatur Efektif dan Kelembaban Relatif

Temperatur dan kelembaban yang didapatkan dari pengukuran menggunakan digital sling pysichrometer akan dimasukan ke dalam kurva temperatur efektif. Gambaran kurva temperatur efektif pada Gambar 1.

Air velocity m/s



Wet bulb temperature ${ }^{\circ} \mathrm{C}$

Gambar 1. Temperatur Efektif [2].

Temperatur efektif yang dianjurkan pada lokasi tambang bawah tanah berkisar antara $18-27^{\circ} \mathrm{C}$. Hal ini berpengaruh terhadap kinerja para pekerja yang berada pada lokasi apabila melebihi atau kurang dari yang dianjurkan.

\section{Menghitung Kebutuhan Udara Pekerja}

Kebutuhan udara untuk pekerja dihitung dengan cara mengalikan jumlah pekerja yang ada dalam lokasi terowongan dengan 8 jam kerja sesuai dengan standar jam kerja.

\section{Menganalisis Faktor Penyebab Kecelakaan Kerja}

Kecelakaan kerja yang mengakibatkan kematian dua (2) orang pekerja akan dianalisis dengan melihat hasil pengukuran kandungan gas, kuantitas udara dan investigasi dari lapangan.

\section{Rancangan Ventilasi}

Perancangan sistem ventilasi yang aman disesuaikan dengan nilai ambang batas dari semua aspek ventilasi dengan menghitung keseluruhan yang disesuaikan dengan standar ventilasi.

\section{Analisis Data Penelitian}

Analisis data dilakukan berdasarkan hasil pengukuran kondisi aktual lapangan di lokasi tambang bawah tanah BMK 35 Lori 4 disesuaikan dengan standar ventilasi berdasarkan Keputusan Direktur Jendral Mineral dan Batubara Menteri Pertambangan dan Energi Nomor 185 K/37.04/DJB/2019.

\section{HASIL DAN PEMBAHASAN}

\section{Pengukuran Gas}

Pengukuran gas pada lokasi lubang tambang BMK Lori 4 dilakukan selama 10 hari dari tanggal 9-18 Maret 2021 setiap pagi dan siang hari dengan menggunakan alat multigas detector. Proses pengukuran dapat dilihat pada Gambar 2

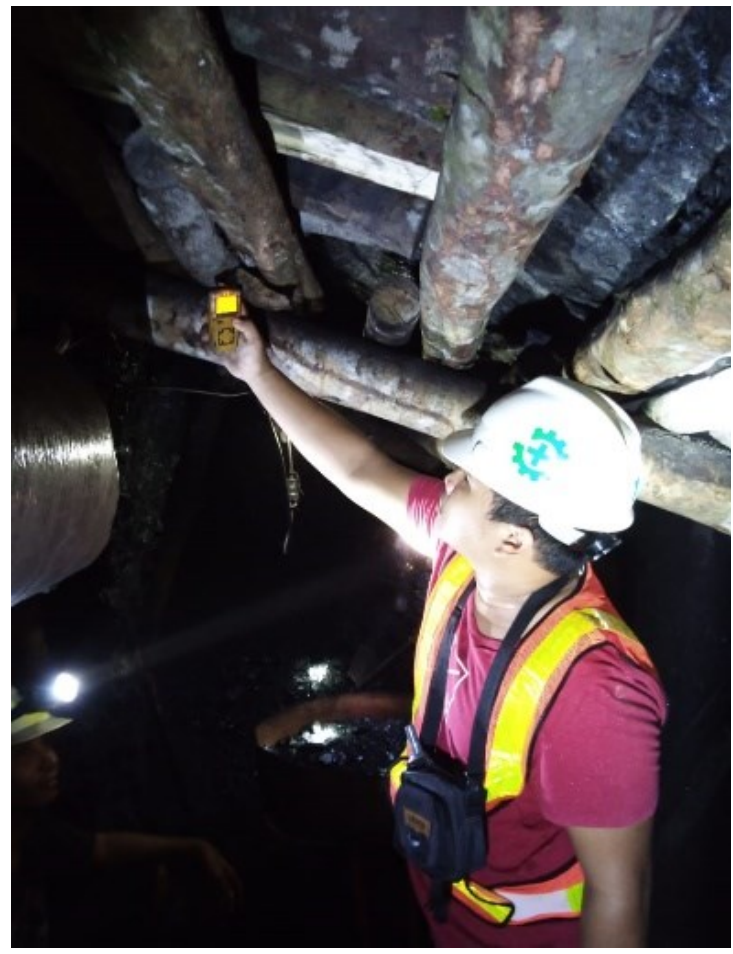

Gambar 2. Pengukuran Gas

Alat multigas detector dapat membaca konsentrasi empat (4) macam gas yaitu methan, oksigen, karbon monoksida, dan hidrogen sulfida.

\section{Pengukuran Gas Metana}

Hasil pengukuran gas metana dapat dilihat pada Tabel 1 berikut ini. 
Tabel 1. Pengukuran Gas Methana

\begin{tabular}{|c|c|c|c|c|c|c|c|c|c|c|}
\hline \multirow{3}{*}{ Tanggal } & \multicolumn{10}{|c|}{ Gas Metana [CH4 (LEL)] } \\
\hline & \multicolumn{2}{|c|}{ Kanopi } & \multicolumn{2}{|c|}{ Jalur } & \multicolumn{2}{|c|}{ FK } & \multicolumn{2}{|c|}{ C6 } & \multicolumn{2}{|c|}{$\begin{array}{c}\text { Jalur } \\
\text { Ventilasi }\end{array}$} \\
\hline & Pagi & Siang & Pagi & Siang & Pagi & Siang & Pagi & Siang & Pagi & Siang \\
\hline 09-Mar-21 & 0 & 0 & 4 & 3 & 5 & 4 & 5 & 2 & 0 & 0 \\
\hline 10-Mar-21 & 0 & 0 & 3 & 4 & 6 & 5 & 3 & 4 & 0 & 0 \\
\hline 11-Mar-21 & 0 & 0 & 3 & 6 & 5 & 5 & 6 & 5 & 0 & 0 \\
\hline 12-Mar-21 & 0 & 0 & 3 & 2 & 6 & 4 & 3 & 5 & 0 & 0 \\
\hline 13-Mar-21 & 0 & 0 & 4 & 1 & 5 & 3 & 1 & 0 & 0 & 0 \\
\hline 14-Mar-21 & 0 & 0 & 2 & 4 & 5 & 8 & 1 & 0 & 0 & 0 \\
\hline 15-Mar-21 & 0 & 0 & 4 & 2 & 5 & 4 & 3 & 5 & 0 & 0 \\
\hline 16-Mar-21 & 0 & 0 & 3 & 1 & 6 & 3 & 1 & 4 & 0 & 0 \\
\hline 17-Mar-21 & 0 & 0 & 3 & 5 & 2 & 1 & 4 & 7 & 0 & 0 \\
\hline 18-Mar-21 & 0 & 0 & 0 & 2 & 5 & 3 & 3 & 2 & 0 & 0 \\
\hline
\end{tabular}

Didapatkan kandungan gas metana yang terdapat pada lokasi jalur, FK, C6, dan jalur ventilasi. Akan tetapi kandungan tertinggi terdapat pada lokasi C6 tanggal 17 Maret 2021 sebesar 7 LEL setara dengan 0,35 \% dimana kondisi ini melebihi nilai ambang batas yang ditetapkan oleh Keputusan Direktur Jendral Mineral dan Batubara Menteri Pertambangan dan Energi Nomor 185 K/37.04/DJB/2019 sebesar 0,25\%. Apabila melebihi standar tersebut dapat menimbulkan ledakan tambang. Pada tambang batubara bawah tanah akumulasi gas metana berasal dari lapisan batubara dan batuan di sekelilingnya yang terbebaskan pada saat kegiatan pembukaan lubang bukaan tambang $[1,3]$.

\section{Pengukuran Gas Hidurogen Sulfida $\left(\mathrm{H}_{2} \mathrm{~S}\right)$}

Gas hidrogen sulfida disebut juga gas busuk (stinkdamp). Hal ini dikarenakan gas tersebut berbau telur busuk. Karakter gas ini tidak bewarna, beracun, dan dapat meledak, dekomposisi dari belerang. Berdasarkan hasil pengukuran yang dapat dilihat pada Tabel 2, tidak ditemukan kandungan gas hirogen sulfida pada lokasi lubang bukaan tambang BMK 35 lori 4 sehingga pada lokasi tersebut dinyatakan aman untuk dilakukan kegiatan penambangan.

Tabel 2. Pengukuran Hidrogen Sulfida

\begin{tabular}{ccccccccccc}
\hline \multirow{2}{*}{ Tanggal } & \multicolumn{1}{c}{ Kas H2S (PPM) } \\
\cline { 2 - 11 } & \multicolumn{2}{c}{ Kanopi } & \multicolumn{2}{c}{ Jalur } & \multicolumn{2}{c}{ FK } & \multicolumn{2}{c}{ C6 } & $\begin{array}{c}\text { Jalur } \\
\text { Ventilasi }\end{array}$ \\
\cline { 2 - 11 } & Pagi & Siang & Pagi & Siang & Pagi & Siang & Pagi & Siang & Pagi & Siang \\
\hline 09-Mar-21 & 0 & 0 & 0 & 0 & 0 & 0 & 0 & 0 & 0 & 0 \\
10-Mar-21 & 0 & 0 & 0 & 0 & 0 & 0 & 0 & 0 & 0 & 0 \\
11-Mar-21 & 0 & 0 & 0 & 0 & 0 & 0 & 0 & 0 & 0 & 0 \\
12-Mar-21 & 0 & 0 & 0 & 0 & 0 & 0 & 0 & 0 & 0 & 0 \\
13-Mar-21 & 0 & 0 & 0 & 0 & 0 & 0 & 0 & 0 & 0 & 0 \\
14-Mar-21 & 0 & 0 & 0 & 0 & 0 & 0 & 0 & 0 & 0 & 0 \\
15-Mar-21 & 0 & 0 & 0 & 0 & 0 & 0 & 0 & 0 & 0 & 0 \\
16-Mar-21 & 0 & 0 & 0 & 0 & 0 & 0 & 0 & 0 & 0 & 0 \\
17-Mar-21 & 0 & 0 & 0 & 0 & 0 & 0 & 0 & 0 & 0 & 0 \\
18-Mar-21 & 0 & 0 & 0 & 0 & 0 & 0 & 0 & 0 & 0 & 0 \\
\hline
\end{tabular}




\section{Pengukuran Gas Karbon Monoksida (CO)}

Terdapatnya gas CO biasanya ditemukan setelah kegiatan peledakan dan penggalian jalan utama yang dipengaruhi oleh jarak antara mulut saluran udara dan permukaan kerja [4]. Hasil pengukuran dapat dilihat pada Tabel 3.
Berdasarkan hasil pengukuran di lapangan kandungan gas karbon monoksida didapatkan pada dua (2) lokasi yaitu FK dan C6 dimana pada lokasi tersebut memiliki konsentrasi yang tinggi hingga 36 ppm setara dengan $0,0036 \%$ sehingga mendekati nilai ambang batas yang ditetapkan oleh Keputusan Direktur Jendral Mineral dan Batubara Menteri Pertambangan dan Energi Nomor 185 K/37.04/DJB/2019 sebesar 0,005\%. Apabila melebihi standar tersebut dapat mengakibatkan kematian.

Tabel 3. Pengukuran CO

\begin{tabular}{|c|c|c|c|c|c|c|c|c|c|c|}
\hline \multirow{3}{*}{ Tanggal } & \multicolumn{10}{|c|}{ Gas CO (PPM) } \\
\hline & \multicolumn{2}{|c|}{ Kanopi } & \multicolumn{2}{|c|}{ Jalur } & \multicolumn{2}{|c|}{ FK } & \multicolumn{2}{|c|}{ C6 } & \multicolumn{2}{|c|}{$\begin{array}{c}\text { Jalur } \\
\text { Ventilasi }\end{array}$} \\
\hline & Pagi & Siang & Pagi & Siang & Pagi & Siang & Pagi & Siang & Pagi & Siang \\
\hline 09-Mar-21 & 0 & 0 & 0 & 0 & 20 & 15 & 18 & 25 & 0 & 0 \\
\hline 10-Mar-21 & 0 & 0 & 0 & 0 & 30 & 28 & 25 & 33 & 0 & 0 \\
\hline 11-Mar-21 & 0 & 0 & 0 & 0 & 30 & 32 & 18 & 21 & 0 & 0 \\
\hline 12-Mar-21 & 0 & 0 & 0 & 0 & 28 & 34 & 27 & 19 & 0 & 0 \\
\hline 13-Mar-21 & 0 & 0 & 0 & 0 & 30 & 36 & 11 & 9 & 0 & 0 \\
\hline 14-Mar-21 & 0 & 0 & 0 & 0 & 32 & 35 & 13 & 11 & 0 & 0 \\
\hline 15-Mar-21 & 0 & 0 & 0 & 0 & 29 & 36 & 14 & 17 & 0 & 0 \\
\hline 16-Mar-21 & 0 & 0 & 0 & 0 & 28 & 32 & 27 & 19 & 0 & 0 \\
\hline 17-Mar-21 & 0 & 0 & 0 & 0 & 30 & 30 & 18 & 21 & 0 & 0 \\
\hline 18-Mar-21 & 0 & 0 & 0 & 0 & 29 & 34 & 27 & 29 & 0 & 0 \\
\hline
\end{tabular}

\section{Pengukuran Oksigen $\left(\mathrm{O}_{2}\right)$}

Berdasarkan hasil pengukuran di lapangan didapatkan konsentrasi oksigen di bawah nilai ambang batas yang terdapat pada lokasi FK dan C6, dimana kandungan oksigen yang kurang dari nilai ambang batas dapat menyebabkan resiko yang besar pada saat kegiatan penambangan berlangsung (Tabel 4).

Tabel 4. Pengukuran Oksigen

\begin{tabular}{|c|c|c|c|c|c|c|c|c|c|c|}
\hline \multirow{3}{*}{ Tanggal } & \multicolumn{10}{|c|}{$\mathrm{O} 2 \%$} \\
\hline & \multicolumn{2}{|c|}{ Kanopi } & \multicolumn{2}{|c|}{ Jalur } & \multicolumn{2}{|c|}{ FK } & \multicolumn{2}{|c|}{ C6 } & \multicolumn{2}{|c|}{ Jalur Ventilasi } \\
\hline & Pagi & Siang & Pagi & Siang & Pagi & Siang & Pagi & Siang & Pagi & Siang \\
\hline 09-Mar-21 & 20,1 & 20,1 & 20 & 20,3 & 19,1 & 19,3 & 19 & 19,4 & 20,1 & 20,2 \\
\hline 10-Mar-21 & 20,1 & 20,3 & 20,1 & 20,3 & 19,1 & 19,3 & 18,7 & 19,1 & 20,2 & 20,2 \\
\hline 11-Mar-21 & 20,1 & 20,1 & 20,1 & 20,4 & 19,1 & 19,1 & 19 & 19,2 & 20,1 & 20,1 \\
\hline 12-Mar-21 & 20,2 & 20,1 & 20,1 & 20,1 & 19,1 & 19 & 18,7 & 19,1 & 20,1 & 20,2 \\
\hline 13-Mar-21 & 20,1 & 20,1 & 20,1 & 20,1 & 19 & 19,1 & 19 & 19,1 & 20,1 & 20,2 \\
\hline 14-Mar-21 & 20,1 & 20,1 & 20,1 & 20,1 & 19 & 19,1 & 18 & 19,1 & 20,1 & 20,1 \\
\hline 15-Mar-21 & 20,1 & 20,1 & 20,1 & 20,4 & 19 & 19,1 & 19 & 19,2 & 20,1 & 20,2 \\
\hline 16-Mar-21 & 20,1 & 20,1 & 20,1 & 20,4 & 19 & 19,1 & 19 & 19,2 & 20,1 & 20,2 \\
\hline 17-Mar-21 & 20,1 & 20,1 & 20,1 & 20,4 & 19,2 & 19,1 & 19 & 19,2 & 20,1 & 20,1 \\
\hline 18-Mar-21 & 20,2 & 20,1 & 20,1 & 20,1 & 19,1 & 19 & 19 & 19,1 & 20,1 & 20,2 \\
\hline
\end{tabular}


Kondisi ini sangat berbahaya bagi para pekerja di lapangan karena oksigen yang berada pada kedua lokasi tersebut dapat menyebabkan sulit bernapas dan tidak sesuai dengan Keputusan Direktur Jendral Mineral dan Batubara Menteri Pertambangan dan Energi Nomor 185 $\mathrm{K} / 37.04 / \mathrm{DJB} / 2019$ sebesar $19,5 \%$.

\section{Pengukuran Lubang Bukaan}

Pengukuran dilakukan di beberapa lokasi, mulai dari kanopi, jalur, front kerja, cabang C6, dan jalur ventilasi. Pengukuran pada lima (5) lokasi tersebut dikarenakan lokasi tersebut memiliki bentuk penampang dan luasan yang berbeda, oleh sebab itu harus dilakukan pengukuran per lokasi. Hasil dari pengukuran dapat dilihat pada Tabel 5 berikut ini.

Tabel 5. Pengukuran Luas Penampang

\begin{tabular}{|c|c|c|c|c|}
\hline No & $\begin{array}{c}\text { Lebar } \\
\text { Bawah (W) } \\
\text { (Meter) }\end{array}$ & $\begin{array}{c}\text { Lebar } \\
\text { Atas } \\
(\mathrm{T}) \\
\text { (Meter) }\end{array}$ & $\begin{array}{l}\text { Tinggi } \\
(\mathrm{H}) \\
\text { (Meter) }\end{array}$ & $\begin{array}{c}\text { Luas } \\
\text { Penampang } \\
\text { (Meter) }\end{array}$ \\
\hline Kanaopi & 3.1 & 3.1 & 3,4 & 12,98 \\
\hline Jalur & 2,5 & 2,2 & 2,8 & 3,94 \\
\hline $\begin{array}{l}\text { Front } \\
\text { Kerja }\end{array}$ & 2,4 & 2,1 & 2.5 & 5,6 \\
\hline $\begin{array}{c}\text { Cabang } \\
\text { C6 }\end{array}$ & 2,4 & 2 & 2,5 & 5,3 \\
\hline $\begin{array}{c}\text { Jalur } \\
\text { Ventilasi }\end{array}$ & 2,1 & 1,7 & 2.2 & 4,18 \\
\hline
\end{tabular}

Berdasarkan hasil pengukuran lubang bukaan, kondisi lubang bukaan yang ukurannya tidak sama sehingga berpengaruh terhadap bentuk lubang bukaan yang tidak beraturan.

\section{Pengukuran Debit}

Pengukuran kecepatan udara dilakukan dengan menggunakan alat anemometer dilakukan di lima (5) lokasi (Tabel 6).

Tabel 6. Pengukuran Debit Udara

\begin{tabular}{lccc}
\hline Lokasi & $\begin{array}{c}\text { Kecepatan } \\
\text { Udara }(\mathrm{m} / \mathrm{s})\end{array}$ & $\begin{array}{c}\text { Luas } \\
\text { Penampang } \\
\left(\mathrm{m}^{2}\right)\end{array}$ & $\begin{array}{c}\text { Debit } \\
\mathrm{m}^{3} / \mathrm{det}\end{array}$ \\
\hline Kanopi & 0,2 & 12,98 & 2,596 \\
Jalur & 0,4 & 5,8 & 2,32 \\
Front Kerja & 0,3 & 5,6 & 1,68 \\
Cabang & 0,15 & 5,3 & 0,795 \\
C 6 & & & \\
Jalur & 0,22 & 4,18 & 0,9196 \\
Ventilasi & & & \\
\hline
\end{tabular}

Berdasarkan tabel di atas diketahui debit tertinggi pada lokasi kanopi dan debit terendah didapatkan pada cabang C6.

\section{Pengukuran Temperatur Efektif}

Pengukuran temperatur efektif dilakukan di lima (5) stasiun pengukuran dengan menggunakan alat digital sling pysicometer. Hasil pengukuran dapat dilihat pada Tabel 7.

Tabel 7. Pengukuran Temperatur Efektif

\begin{tabular}{ccccc}
\hline \multirow{2}{*}{ Lokasi } & \multicolumn{2}{c}{ Suhu $\mathrm{F}$} & $\begin{array}{c}\text { Kecepatan } \\
\text { Udara }\end{array}$ & $\begin{array}{c}\text { Temperatu } \\
\text { r Efektif }\end{array}$ \\
\cline { 2 - 4 } & TD & TW & ft/menit & \\
\hline Kanopi & 86,468 & $\begin{array}{c}86,46 \\
8\end{array}$ & 0,2 & 30 \\
Jalur & 84,2 & 84,2 & 0,4 & 29 \\
$\begin{array}{c}\text { Front } \\
\text { kerja }\end{array}$ & 83,552 & 83,57 & 0,3 & 29,3 \\
$\begin{array}{c}\text { Cabang } \\
\text { C 6 }\end{array}$ & 83,4 & 83,4 & 0,15 & 28,8 \\
$\begin{array}{c}\text { Jalur } \\
\text { ventilas } \\
\text { i }\end{array}$ & 83,4 & 83,4 & 0,22 & 28,7 \\
\hline
\end{tabular}

Berdasarkan hasil pengukuran didapatkan nilai temperatur efektif yang berada pada lokasi lebih dari $27^{\circ} \mathrm{C}$ sehingga melebihi nilai standar yang ditentukan.

\section{Pengukuran Kelembaban Relatif}

Berdasarkan hasil pengukuran kelembaban relatif pada lokasi lubang bukaan BMK 35 Lori 4 di lima (5) stasiun pantau hasil yang dapat dilihat di Tabel 8 berikut ini.

Tabel 8. Pengukuran Kelembaban Relatif

\begin{tabular}{cccccc}
\hline & \multicolumn{5}{c}{ RH $(\%)$} \\
\cline { 2 - 6 } Tanggal & Kanopi & Jalur & FK & C6 & $\begin{array}{c}\text { Jalur } \\
\text { Ventilasi }\end{array}$ \\
\hline 09-Mar-21 & 97 & 97 & 99 & 97 & 98 \\
10-Mar-21 & 97 & 98 & 99 & 97 & 98 \\
11-Mar-21 & 97 & 98 & 99 & 97 & 98 \\
12-Mar-21 & 97 & 98 & 99 & 97 & 98 \\
13-Mar-21 & 97 & 98 & 99 & 98 & 98 \\
14-Mar-21 & 97 & 98 & 99 & 98 & 98 \\
15-Mar-21 & 89,2 & 97 & 98 & 98 & 97 \\
16-Mar-21 & 97 & 98 & 99 & 97 & 98 \\
17-Mar-21 & 97 & 98 & 99 & 97 & 98 \\
18-Mar-21 & 97 & 98 & 99 & 97 & 98 \\
\hline
\end{tabular}


Dari pengukuran didapatkan nilai kelembaban relatif yang melebih standar Keputusan Direktur Jendral Mineral dan Batubara Menteri Pertambangan dan Energi Nomor 185 K/37.04/DJB/2019 bahwa kelembaban relatif tidak boleh lebih dari $85 \%$ sedangkan kelembaban yang didapatkan di atas $85 \%$. Hal ini menunjukkan bahwa lokasi tersebut sangat lembab yang akan berpengaruh pada aktivitas para pekerja di lokasi [5].

\section{Kebutuhan Udara Pekerja}

Kebutuhan udara pekerja berdasarkan Keputusan Dirjen Minerba No. 185.K/3.04/DJB/2019 dijelaskan tentang pemenuhan kebutuhan udara di dalam tambang untuk pekerja dan peralatan tambang yang bekerja [6]. Hasil pengukuran kebutuhan udara pekerja dapat dilihat pada Tabel 9 berikut ini.

Tabel 9. Kebutuhan Udara Pekerja

\begin{tabular}{lcc}
\hline Lokasi & Jumlah Pekerja & $\begin{array}{c}\text { Kebutuhan } \\
\text { Udara } \text { m }^{3} \text { detik }\end{array}$ \\
\hline Kanopi & 2 & 0,06 \\
Jalur & 2 & 0,06 \\
Front Kerja & 6 & 0,198 \\
FK & 6 & 0,198 \\
Cabang C6 & 2 & 0,06 \\
$\begin{array}{l}\text { Jalur } \\
\text { Ventilasi }\end{array}$ & $\begin{array}{l}\text { Jumlah udara yang di } \\
\text { perlukan }\end{array}$ & 0,1152 \\
\hline
\end{tabular}

Dalam pasal 21 dijelaskan volume udara bersih di sistem ventilasi wajib diperhatikan berdasarkan jumlah pekerja tidak kurang dari $2 \mathrm{~m}^{3} /$ menit $\left(0,03 \mathrm{~m}^{3} / \mathrm{s}\right)$ selama pekerjaan berlangsung. Kebutuhan udara peralatan mekanis adalah $0,05 \mathrm{~m}^{3} /$ detik per $1 \mathrm{hp}$.

\section{Faktor-Faktor Penyebab Terjadinya Kecelakaan Korban Meninggal Akibat Gas di BMK 35 Lori 4}

1. Penyebab Langsung

a. Kondisi Tidak Aman

Front kerja yang masih terasa hangat, kadar oksigen $14 \%$ di bawah standar. Portal dan rambu yang digunakan kurang memadai, sehingga bisa memberi celah kepada pekerja untuk bisa melewatinya. b. Tindakan Tidak Aman

- Pekerja tambang memasuki area yang telah dibarikade/diportal dan diberi rambu larangan pada daerah yang tidak dialiri oleh udara bersih atau ventilasi peranginan.

- Berusaha menolong korban dengan inisiatif sendiri tanpa meminta pertolongan terlebih dahulu ke luar tambang.

c. Tidak memastikan terlebih dahulu kadar oksigen dan gas sebelum melakukan pertolongan pada korban, yang mengakibatkan adanya korban tambahan karena kekurangan oksigen.

d. Motivasi keliru menganggap gampang daerah bahaya.

\section{Rancangan Sistem Ventilasi yang Aman di BMK 35 Lori 4}

Lokasi BMK 35 lori 4 memiliki sistem ventilasi dengan prinsip hembus dengan menggunakan blower. Blower dipasang pada lokasi yang akan dialirkan udara untuk memeberikan oksigen dan memecah konsentrasi gasgas berbahaya sehingga dapat teruraikan serta berperan untuk menurunkan temperatur yang ada pada lokasi.

Pada lokasi cabang C6 dipasang blower 14" dan 12" dan lokasi front kerja FK dipasang blower 14" dikarenakan pada lokasi tersebut merupakan tempat kegiatan penambangan yang masih aktif dan juga lokasi tersebut memiliki kandungan gas methan dan gas $\mathrm{CO}$ yang tinggi. Walaupun pada lokasi tersebut telah dipasang blower akan tetapi belum mampu memecah konsentrasi gas berbahaya secara maksimal. Posisi aktual ventilasi dapat dilihat pada Gambar 3.

Simulasi aktual dilakukan dengan menggunakan software ventsim visual $[7,8]$ dimana data yang diperlukan adalah :

1. Data pengukuran luas penampang

2. Data blower yang digunakan

3. Data kecepatan udara

4. Layout BMK 35 lori 4

5. Data kandungan gas

Data-data tersebut akan dimasukan ke dalam parameter ventsim visual untuk mengetahui kondisi yang sebenarnya (Gambar 4). 


\section{Jurnal Pertambangan}

\section{http://ejournal.ft.unsri.ac.id/index.php/JP}

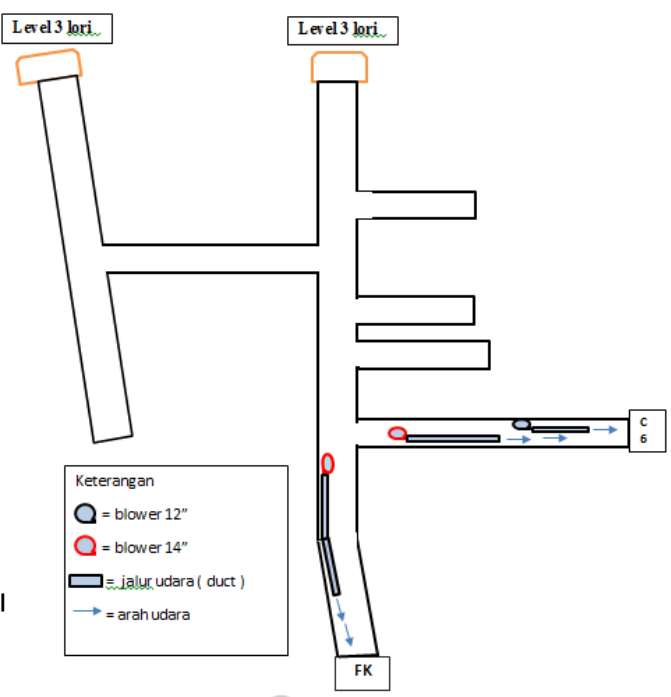

Gambar 3. Kondisi Aktual Lokasi Ventilasi

Berdasarkan hasil simulasi dari software ventsim [9] di mana didapatkan kondisi udara yang ada pada lubang tambang BMK 35 Lori 4 relatif aman akan tetapi kondisi yang aman berdasarkan software berbeda dengan kondisi sebenarnya di lapangan. Kondisi sebenarnya di lapangan, kandungan gas berbahaya pada cabang C6 dan front kerja memiliki kandungan gas methan dan $\mathrm{CO}$ yang masih melebihi nilai ambang batas yang ditetapkan.

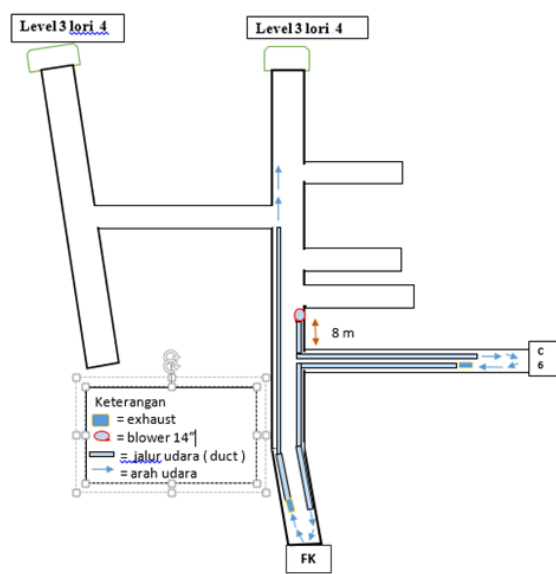

Gambar 5. Rancangan Ventilasi

Rancangan ventilasi mengacu kepada sistem ventilasi dengan sistem forcing overlap ventilasi dimana perpaduan antara sistem hembus dan sistem hisap dengan menempatkan blower pada lokasi 8 meter sebelum cabang C6 dengan saluran udara yang masuk,

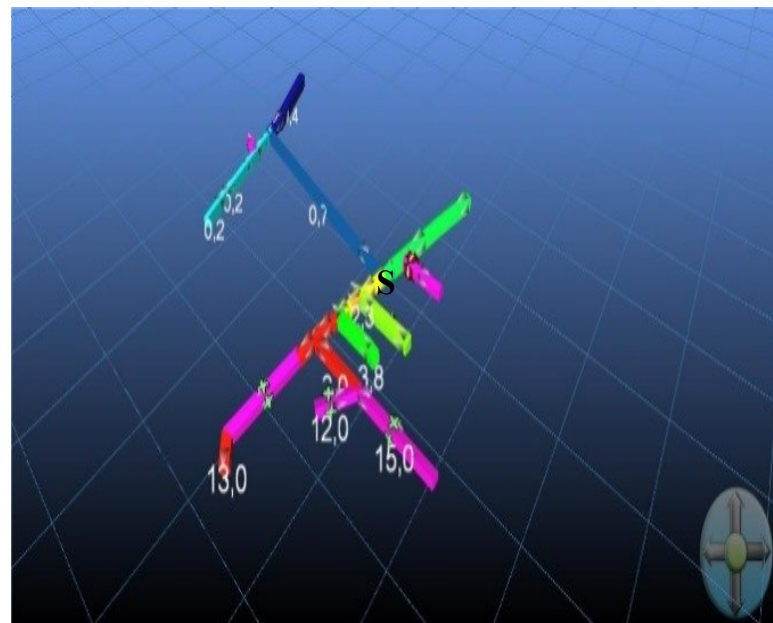

Gambar 4. Kondisi Aktual Ventilasi dengan Ventsim

Hal tersebut menunjukkan bahwa suplai udara belum mampu secara maksimal untuk dapat mengurai konsentrasi gas-gas berbahaya walaupun udara pada lokasi sudah sesuai standar. Untuk itu perencanaan ventilasi harus diperhatikan agar dapat menetralkan gas yang terdapat pada lokasi lubang BMK 35 level 3 lori 4. Perencanaan dapat dilihat pada Gambar 5 dan 6 berikut.



Gambar 6. Rancangan Ventilasi dengan Ventsim Visual.

dan selanjutnya pada dekat lokasi kerja dipasang exhaust untuk menarik udara segar yang tersirkulasi ke lokasi front kerja (FK) maju. Pada lokasi front kerja ditambahkan satu (1) exhaust agar membantu menarik udara keluar menuju pintu masuk melalui jalur udara. 
Perencanaan ventilasi ini dirancang untuk membawa dan menetralkan gas-gas berbahaya yang berada pada lokasi [10].

\section{KESIMPULAN}

Kondisi aktual kandungan gas dan udara di BMK 35 Lori 4 melebihi standar yaitu sebesar 7 LEL atau setara dengan $0,35 \%$. Selanjutnya gas $\mathrm{CO}$ yang masih terdapat pada lokasi tersebut sebesar 36 PPM atau setara dengan $0,0036 \%$ yang merupakan faktor penyebab terjadinya kecelakaan kerja.

Berdasarkan rancangan ventilasi yang dilakukan di BMK 35 Lori 4 dengan menerapkan sistem forcing overlap yang disimulasikan dengan menggunakan sofware ventsim visual menggambarkan bahwa rancangan tersebut mampu mensuplai udara dengan tidak terjadinya sirkulasi ulang untuk dapat masuk ke dalam lokasi lubang bukaan, menurunkan temperatur, kelembaban, dan juga dapat memecah konsentrasi gasgas berbahaya yang berada pada C6 dan FK.

\section{UCAPAN TERIMA KASIH}

Terimaksih kepada CV. Bara Mitra Kencana yang memberikan izin untuk melakasanakan penelitian dan juga ucapan terimakasih kepada Universitas Sriwijaya khususnya Jurusan Magister Teknik Pertambangan yang memberi dukungan dalam penelitian ini.

\section{DAFTAR PUSTAKA}

[1] Hartman, H. L., Mutmansky, J. M., Ramani, R. V. (Raja V. ., \& Wang, Y. J. (2012). Coal Mine Ventilation Systems (pp. 455-524). Wiley.

[2] Heriyadi, B. (2017). Rancangan Dan Pembuatan Alat Simulasi Sistem Ventilasi Tambang Pada Laboratorium Untuk Pembelajaran Ventilasi Tambang. Jurnal Sains Dan Teknologi: Jurnal Keilmuan Dan Aplikasi Teknologi Industri, 17(2);147.https://doi.org/10.36275/stsp.v17i2.7 4.

[3] Singh, H., \& Mallick, J. (2015). Utilization of Ventilation Air Methane in Indian Coal Mines: Prospects and Challenges. Procedia Earth and Planetary Science, 11, 56-62. https://doi.org/10.1016/j.proeps.2015.06.008.
[4] Huang, R., Shen, X., Wang, B., \& Liao, X. (2020). Migration characteristics of $\mathrm{CO}$ under forced ventilation after excavation roadway blasting: A case study in a plateau mine. Journal of Cleaner Production, 267, 122094. https://doi.org/10.1016/j.jclepro.2020.122094.

[5] Nata, R. A., \& Nanda, H. F. (2019). Analysis on Ventilation System in Holes C1 Underground Mines of Pt. Nusa Alam Lestari, Desa Salak, Kecamatan Talawi, Sawahlunto, West Sumatera. Jurnal GEOSAPTA, 5(2), 115. https://doi.org/10.20527/jg.v5i2.6085.

[6] Kementerian Energi dan Sumber Daya Mineral. (2019). Kepdirjen Minerba Kementerian Energi dan Sumber Daya Mineral Nomor 185.K/37.04/DJB/2019 tentang Petunjuk Teknis Pelaksanaan Keselamatan Pertambangan dan Pelaksanaan, Penilaian, dan Pelaporan Sistem Manajemen Keselamatan Pertambangan.

[7] Feng, W., Zhu, F., \& Lv, H. (2011). The use of 3D simulation system in mine ventilation management. Procedia Engineering, 26, 13701379.

https://doi.org/10.1016/j.proeng.2011.11.2313.

[8] Sestiana, R., \& Heriyadi, B. (2019). Perencanaan Sistem Ventilasi Pada Tambang Batubara Bawah Tanah Seam C2 Di PT. Nusa Alam Letari, Desa Salak, Kecamatan Talawi, Kota Sawahlunto, Sumatera Barat. Jurnal Bina Tambang, 4(2), 39-48.

[9] Syaputra, D., \& Heriyadi, B. (2019). Analisis Pengaruh Kecepatan Aliran Udara Terhadap Penurunan Temperatur Efektif Pada Alat Simulasi Ventilasi Tambang Bawah Tanah. Jurnal Bina Tambang. Vol. 4 No. 1.

[10] Widodo, N. P. (2015). Studi Mengenai Ventilasi Tambang Batubara Bawah Tanah PT XYZ Dengan Menggunakan Perangkat Lunak Ventsim Visual 3 Tanah PT XYZ Dengan Menggunakan Perangkat Lunak. August 2019 Prosiding Tpt Xxiv Dan Kongres Perhapi Ix 2015 (2015) (August 2019). 